\title{
Transendothelial movement of adiponectin is restricted by glucocorticoids
}

\author{
Thanh Q Dang1,*, Nanyoung Yoon 1,*, Helen Chasiotis', Emily C Dunford², \\ Qilong Feng ${ }^{3}$, Pingnian $\mathrm{He}^{3}$, Michael C Riddell ${ }^{2}$, Scott P Kelly ${ }^{1}$ and Gary Sweeney ${ }^{1}$
}

1Department of Biology, Faculty of Science York University, Toronto, Canada

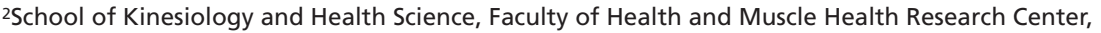
York University, Toronto, Canada

${ }^{3}$ Department of Cellular and Molecular Physiology, College of Medicine, Pennsylvania State University, Hershey, PA, USA

*(T Q Dang and N Yoon contributed equally to this work)

Correspondence should be addressed to G Sweeney

Email

gsweeney@yorku.ca

\begin{abstract}
Altered permeability of the endothelial barrier in a variety of tissues has implications both in disease pathogenesis and treatment. Glucocorticoids are potent mediators of endothelial permeability, and this forms the basis for their heavily prescribed use as medications to treat ocular disease. However, the effect of glucocorticoids on endothelial barriers elsewhere in the body is less well studied. Here, we investigated glucocorticoid-mediated changes in endothelial flux of Adiponectin (Ad), a hormone with a critical role in diabetes. First, we used monolayers of endothelial cells in vitro and found that the glucocorticoid dexamethasone increased transendothelial electrical resistance and reduced permeability of polyethylene glycol (PEG, molecular weight $4000 \mathrm{Da}$ ). Dexamethasone reduced flux of Ad from the apical to basolateral side, measured both by ELISA and Western blotting. We then examined a diabetic rat model induced by treatment with exogenous corticosterone, which was characterized by glucose intolerance and hyperinsulinemia. There was no change in circulating Ad but less Ad protein in skeletal muscle homogenates, despite slightly higher mRNA levels, in diabetic vs control muscles. Dexamethasone-induced changes in Ad flux across endothelial monolayers were associated with alterations in the abundance of select claudin tight junction (TJ) proteins. shRNA-mediated knockdown of one such gene, claudin-7, in HUVEC resulted in decreased TEER and increased adiponectin flux, confirming the functional significance of Dex-induced changes in its expression. In conclusion, our study identifies glucocorticoid-mediated reductions in flux of Ad across endothelial monolayers in vivo and in vitro. This suggests that impaired Ad action in target tissues, as a consequence of reduced transendothelial flux, may contribute to the glucocorticoid-induced diabetic phenotype.
\end{abstract}

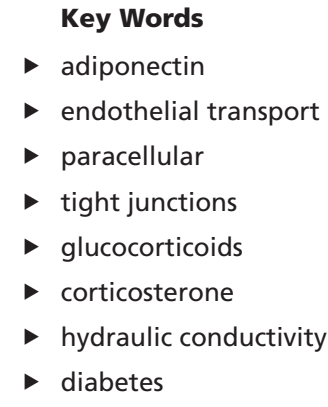

Journal of Endocrinology (2017) 234, 101-114
๑) 2017 Society for Endocrinology Printed in Great Britain
Published by Bioscientifica Ltd 


\section{Introduction}

As the primary barrier to the movement of circulating endocrine factors from the bloodstream to the interstitial space, the endothelium plays a critical role in hormone action (Kolka \& Bergman 2012, Yoon et al. 2014). Endothelial permeability can significantly impact hormone action by preventing or delaying access of the hormone to target tissues (Won et al. 2011, Kolka \& Bergman 2012). Transendothelial solute movement can occur via the transcellular pathway where solutes are transported across the endothelium cell membrane or via the paracellular pathway where solutes passively move through the intercellular space between adjacent endothelial cells (Yoon et al. 2014). Previous work has shown that hormone and nutrient concentrations in blood differ from surrounding cells on the tissue side of the blood vessel endothelium (Yang et al. 1994, Herkner et al. 2003, Barrett et al. 2011). Of note, this has been best documented in the case of insulin where concentrations of the hormone are significantly lower in the target tissue than those in the circulation (Kolka \& Bergman 2012).

Glucocorticoids are among the most commonly prescribed anti-inflammatory and immunosuppressive medications worldwide (Clark \& Belvisi 2012). They are also commonly used in oncology treatment (Lin \& Wang 2016) and for the treatment of macular edema and, more recently, retinopathy (Zhang etal.2014, Agarwal etal.2015). However, glucocorticoids have been shown to have potent effects on restricting endothelial transport (Felinski \& Antonetti 2005, Witt \& Sandoval 2014), and they contribute to the development of diabetes at least in part by increasing hepatic glucose production and reducing GLUT4 translocation in muscle (Beaudry et al. 2015). Yet despite these observations, the potential importance of glucocorticoid-induced alterations in the transendothelial flux of circulating glucoregulatory hormones such as Ad is unclear.

Ad is one of the most abundant plasma proteins and exists in three different isoforms: low molecular weight (LMW; trimer), medium molecular weight (MMW; hexamer) and high molecular weight (HMW; oligomer) (Dadson et al. 2011). Ad has important and beneficial anti-diabetic, anti-inflammatory and cardioprotective actions (Arita et al. 2002, Dadson et al. 2011). Ad levels, in particular HMW, are decreased in obese individuals, and this correlates with the development of associated complications, including diabetes and cardiovascular disease (Kadowaki et al. 2006, Peters et al. 2013). Transendothelial movement of Ad across the blood-brain barrier (BBB) into cerebrospinal fluid (CSF) was studied, and only LMW and MMW were found in the CSF, suggesting that passage of HMW complexes was restricted (Kubota et al. 2007, Kusminski et al. 2007, Neumeier et al. 2007). This may be functionally significant since HMW Ad is often considered to be the most biologically active and physiologically relevant form (Dadson et al. 2011, Nanayakkara et al. 2012). A recent study calculated the Stokes radii for the Ad oligomers and found that endothelial barriers controlled Ad transport in a cell- and tissuespecific manner (Rutkowski et al. 2014). Thus, emerging evidence suggests that Ad action may be at least in part mediated by endothelial transport, although whether this is influenced by glucocorticoid-induced changes in transendothelial permeability remains unknown.

Given the large size of Ad multimers, it seem likely that transendothelial Ad movement is an important variable in determining its presence within, and action on, target tissues. Therefore, we hypothesized that glucocorticoid-induced alterations in transendothelial permeability will modulate the transendothelial movement of Ad. In this regard, the objective of this study was to examine how glucocorticoid treatment of a cultured monolayer of endothelial cells influences $\mathrm{Ad}$ flux in association with changes in permeability and apical junction protein abundance as well as investigate Ad content within the skeletal muscle in a diabetic rat model induced by exogenous glucocorticoid treatment. The overall goal of this work was to significantly advance our understanding of the glucocorticoid-induced diabetic phenotype by determining whether Ad movement out of the circulatory system might play a role in its pathogenesis.

\section{Materials and methods}

\section{HUVEC cell culture and treatments}

Normal primary human umbilical vein endothelial cells (HUVECs; Pooled, PCS-100-013) were obtained from ATCC and grown at $37^{\circ} \mathrm{C}$ and $5 \% \mathrm{CO}_{2}$ on uncoated T75 flasks in vascular cell basal medium (ATCC, PCS-100-030) containing 10\% fetal bovine serum (FBS), VEGF endothelial cell growth kit (ATCC, PCS-100-041) and treated with DEX using 2\% FBS (both medium were prepared without hydrocortisone hemisuccinate), $100 \mathrm{units} / \mathrm{mL}$ penicillin and $100 \mu \mathrm{g} / \mathrm{mL}$ streptomycin. Cells were kept frozen in medium containing 10\% DMSO

Published by Bioscientifica Ltd. 
(Bio-RadLaboratoriesCanadaLtd.).Forexperiments, passage 3 was used. Cells were counted using a hemocytometer and seeded onto permeable polyethylene terephthalate (PET) filters at the base of BD Falcon cell culture inserts (BD Biosciences, Mississauga, ON, Canada) at a density of $0.5 \times 10^{6}$ cells/insert.

Dexamethasone (DEX) was obtained from SigmaAldrich, and full-length Ad was produced in-house using a mammalian expression system (i.e. HEK 293 cells) according to methods described by Wang and coworkers (2002) and Xu and coworkers (2004). 24h after seeding into inserts, HUVECs were treated with Dex $(1 \mu \mathrm{M})$, on both apical and basolateral side, for 5 days.

\section{shRNA-mediated knockdown of claudin-7 in HUVEC}

We used pGPU6/Neo-claudin-7 shRNA vector with target sequence (5'-GGCCATCAGATTGTCACAGAC-3') (GenePharma Co., Ltd., Shanghai, China). These were transfected into HUVEC using Lipofectamine 3000 Reagent (Invitrogen) exactly according to manufacturer's protocol. Non-specific scrambled target sequence shRNA vector was used as control. Following selection with $50 \mathrm{\mu g} / \mathrm{mL}$ Neomycin (Sigma-Aldrich) for $24 \mathrm{~h}$, cells were seeded onto inserts for analysis of TEER, examining adiponectin flux or preparation of cell lysates to confirm claudin-7 knockdown.

\section{Transendothelial electrical resistance (TEER), and [3H]PEG-4000 and Ad flux}

TEER was measured daily using chopstick electrodes (STX-2) connected to an EVOM voltohmmeter (World Precision Instruments, Sarasota, FL, USA). As a measure of paracellular permeability, apical-to-basolateral flux rates of $\left[{ }^{3} \mathrm{H}\right]$ polyethylene glycol at $1 \mu \mathrm{Ci} ; 1 \mathrm{~h}$ flux (molecular mass 4000 Da; PEG-4000; PerkinElmer) or Ad $(10 \mu \mathrm{g} / \mathrm{mL}$; $24 \mathrm{~h}$ flux) to apical culture medium were determined across HUVEC endothelia. [ $\left.{ }^{3} \mathrm{H}\right] \mathrm{PEG}-4000$ in basolateral culture medium was detected using a liquid scintillation counter, Ad was detected using a mouse Ad ELISA kit (Antibody Immunoassay Services, Hong Kong) or Western blot. Permeability measurements were expressed according to calculations previously outlined by Wood and coworkers (Wood et al. 1998).

\section{L6 and $\mathrm{H} 9 \mathrm{C} 2$ cell culture and treatment with HUVEC-conditioned medium}

Rat myoblasts and cardiomyocytes at passage 22-30 were grown in $\alpha \_$AMEM (Life Technologies) and DMEM containing $10 \%$ FBS and 1\% antibiotic-antimycotic (Wisent Inc., St-Bruno, QC, Canada). Culture media from the basolateral compartment of HUVEC inserts were collected and applied. L6/H9C2 cells were starved with medium containing $0.5 \%$ FBS and 1\% antibiotic-antimycotic for $3 \mathrm{~h}$ prior to treatment with HUVEC-conditioned medium.

\section{Quantitative real-time PCR analysis}

Total RNA was isolated from control and DEX-treated HUVECs and from soleus skeletal muscle using TRIzol Reagent. Extracted RNA was then treated with DNase I, and first-strand cDNA was synthesized using SuperScript III reverse transcriptase and oligo(dT) ${ }_{12-18}$ primers (Life Technologies). Quantitative real-time PCR (qRT-PCR) analyses were conducted using gene-specific primers. SYBR Green I Supermix (Bio-Rad Laboratories Canada Ltd.) and a Chromo4 Detection System (CFB-3240; Bio-Rad Laboratories Canada Ltd.) samples were run in duplicate. For all qRT-PCR analyses, TJ protein mRNA expression was normalized to GAPDH transcript abundance. For the expression profile, TJ protein transcripts were expressed relative to occludin mRNA. For TJ protein transcripts that were not detected in HUVECs, normal human adult kidney cDNA was obtained (BioChain Institute, Inc., Newark, CA, USA) and used as a positive control in qRT-PCR reactions. Agarose gel electrophoresis verified single qRT-PCR products at predicted amplicon sizes from positive control reactions.

\section{Animal model of diabetes induced by exogenous corticosterone treatment}

We used a well-established hyperinsulinemic/ hyperglycemic rodent model of chronic glucocorticoid treatment (D'Souza et al. 2012, Shikatani et al. 2012, Shpilberg et al. 2012, Beaudry et al. 2013, 2015). Upon experiment cessation, the tibialis anterior (TA) and soleus skeletal muscles were excised and immediately frozen in liquid $\mathrm{N}_{2}$ and kept at $-80^{\circ} \mathrm{C}$ until future analysis. 


\section{Oral glucose tolerance test}

Animals were fasted overnight (16h), 11 days after pellet implantation, and were administered an oral glucose tolerance test (OGTT, $1.5 \mathrm{~g} / \mathrm{kg}$ body mass) on day $12 \mathrm{using}$ glucometer (Bayer One Touch); additional fasted plasma was collected for later analysis of insulin concentrations via an ELISA 96-well kit (Crystal Chem, USA). Plasma for measurement of Ad concentration was obtained 7 days after pellet implantation at 08:00 $\mathrm{h}$ and assessed using a mouse Ad ELISA kit (AIS, Hong Kong).

\section{Measurement of hydraulic conductivity (Lp) in individually perfused rat mesenteric microvessel}

Female Sprague-Dawley rats of 220-250g (2-3 months old, Sage Laboratory Animal, PA, USA) were used for the experiments. All procedures and animal use were approved by the Animal Care and Use Committee at Pennsylvania State University. Inactin, hydrate (Sigma) was used for anesthesia and given subcutaneously at $170 \mathrm{mg} / \mathrm{kg}$ body weight.

Microvessel permeability was assessed by measuring Lp in individually perfused microvessels, which measures the volume of water flux across the microvessel wall. Details have been described previously (Yuan \& He 2012, Yuan et al. 2014).

\section{Staining for metachromatic myosin ATPase}

To identify skeletal muscle fiber type, a metachromatic myosin ATPase stain was performed using a modified protocol (Ogilvie \& Feeback 1990). Sections were preincubated in an acidic buffer $(\mathrm{pH}=4.25)$ to differentially inhibit myosin ATPase within the different fiber types. In this protocol, type I fibers appear dark blue, type IIa appear light blue and type IIb and IIx are not apparent from each other and are classified as $\mathrm{IIb} / \mathrm{x}$. These fibers appear almost white and are the largest. Images were acquired with a Nikon Eclipse 90i microscope and Q-imaging MicroPublisher with Q-Capture software at $10 \times$ magnification.

\section{Immunohistochemistry of $\mathrm{Ad}$ and dystropin in skeletal muscle}

Tibialis anterior (TA) from control and CORT-treated rats were cryostat sectioned ( $10 \mu \mathrm{m}$ thick) for the analysis of muscle Ad content. Sections were stained as previously described (Krause et al. 2008). Quantification was performed using Zen 2.0 software. The total Ad and dystropin signals were determined by the sum of red/green signal intensity obtained and arbitrary values in the field of view. Diagram view intensity was recorded by the software in the form of histograms. Intracellular quantification was done on $\mathrm{Ad}$ images (without dystropin), images were changed to 8 bits on Image, and the arbitrary intensity was calculated as mean intensity per area.

\section{Western blot analysis}

Control and DEX-treated HUVECs, and L6 or H9C2 cells treated with HUVEC-conditioned medium and soleus skeletal muscle were lysed in sample buffer $(80 \mathrm{mM}$ Tris-HCl (pH 6.8), 2\% (w/v) SDS, 20\% glycerol, 3.3\% $(\mathrm{v} / \mathrm{v}) \beta$-mercaptoethanol and $0.01 \%(\mathrm{w} / \mathrm{v})$ bromophenol blue) containing protease and phosphatase inhibitors (3 mM EDTA, $10 \mu \mathrm{M}$ E64, $1 \mathrm{mM} \mathrm{Na}_{3} \mathrm{VO}_{4}, 1 \mu \mathrm{M}$ leupeptin, $1 \mu \mathrm{M}$ pepstatin $\mathrm{A}, 1 \mu \mathrm{M}$ okadaic acid and $200 \mu \mathrm{M}$ PMSF). Apical and basolateral HUVEC-conditioned media collected from Ad flux experiments were concentrated with Amicon Ultra-4 Centrifugal Filter Units with Ultracel-10K membranes (EMD Millipore) and subjected to nondenaturing, nonreducing conditions to allow the analysis of the different forms of Ad (HMW $>250 \mathrm{kDa}$, MMW $\sim 180 \mathrm{kDa}$, and LMW $\sim 90 \mathrm{kDa}$ ). Primary antibodies are specific for the following proteins: T-cadherin (1:1000, R\&D Systems), occludin (OCLN, 1:3000), tricellulin (TRIC, 1:3000), claudin-7 (CLDN-7, 1:500), CLDN-10 (1:800), CLDN-11 (1:1000), phospho-AMPK $\alpha$ (Thr172) (1:1000), phospho-p38 MAPK (pT180/pY182) (1:1000), Ad (1:1000) and $\beta$-actin (1:1000). OCLN, TRIC, CLDN-7, CLDN-10 and phospho-p38 MAPK (pT180/pY182) antibodies were obtained from Life Technologies, CLDN-11 and Ad antibodies were purchased from EMD Millipore and Signalway Antibody, respectively, and phospho-AMPKo (Thr172) and $\beta$-actin antibodies were obtained from Cell Signaling Technology (New England Biolabs Ltd., Whitby, ON, Canada). Protein was detected using enhanced chemiluminescence (Bio-Rad) and quantification by densitometry using ImageJ analysis software. TJ protein expression was normalized to $\beta$-actin, Tubulin protein abundance.

\section{Statistical analysis}

All data are expressed as mean values \pm S.E.M. A oneway analysis of variance (ANOVA) followed by a

Published by Bioscientifica Ltd 
Student-Newman-Keuls test was used to determine significant differences $(P \leq 0.05)$ between groups. When appropriate, a Student's $t$-test was also used. All statistical analyses were conducted using Prism 5, Excel SigmaStat 3.5 software.

\section{Results}

\section{Dexamethasone induces endothelial tightening and inhibits Ad movement across endothelial cell monolayers}

We first investigated the effect of dexamethasone (DEX), a synthetic glucocorticoid, on tightness of an endothelial monolayer of HUVECs. Addition of DEX to culture media significantly elevated TEER (Fig. 1A) and correspondingly reduced the endothelial permeability of the paracellular transport marker [ $\left.{ }^{3} \mathrm{H}\right]$ PEG-4000 (Fig. 1B). Similar trends regarding permeability were observed in microvessels of DEX-treated rats. DEX treatment $(n=4)$ did not cause a significant reduction in baseline Lp compared to normal control group $(n=6)$, but lowered the mean value from $1.5 \pm 0.1$ to $1.1 \pm 0.2\left(\times 10^{-7} \mathrm{~cm} / \mathrm{s} / \mathrm{cm} \mathrm{H}_{2} \mathrm{O}\right)$. When each vessel was exposed to platelet-activating factor (PAF, $10 \mathrm{nM})$ that is known to cause transient increases in Lp (Zhou \& He 2011), microvessels in DEX-treated rats showed significantly attenuated Lp response. The mean peak Lp value was reduced from $11.1 \pm 1.8$ (normal control) to $6.0 \pm 0.4\left(\times 10^{-7} \mathrm{~cm} / \mathrm{s} / \mathrm{cm} \mathrm{H}_{2} \mathrm{O}\right.$, Fig. 1C).
A

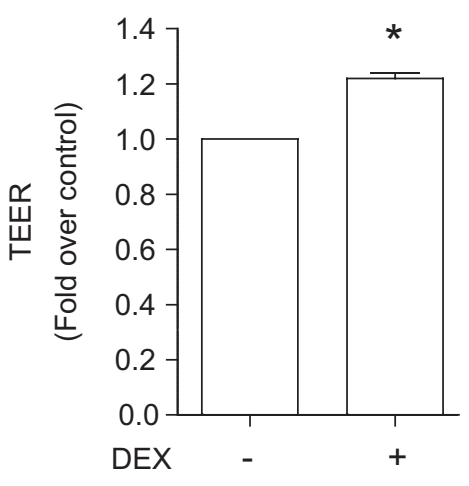

D

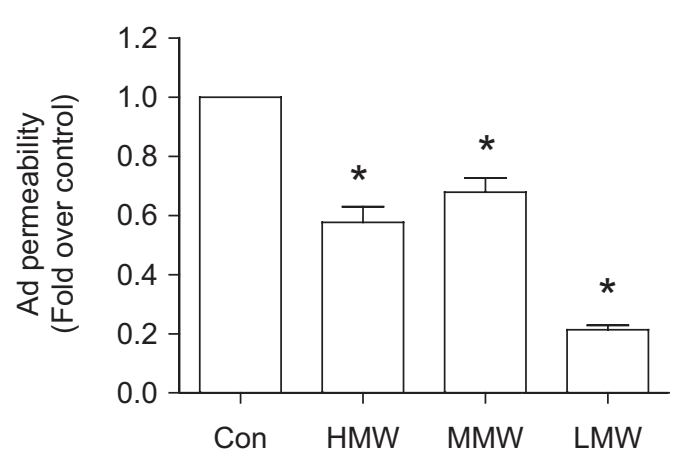

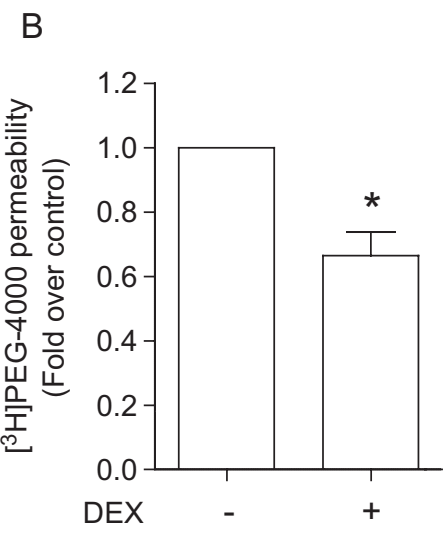

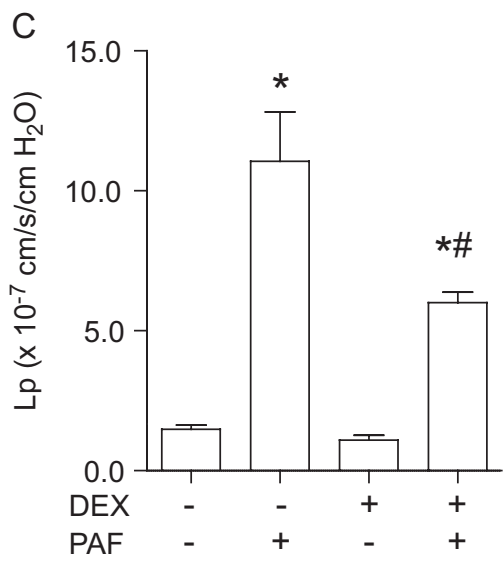

E

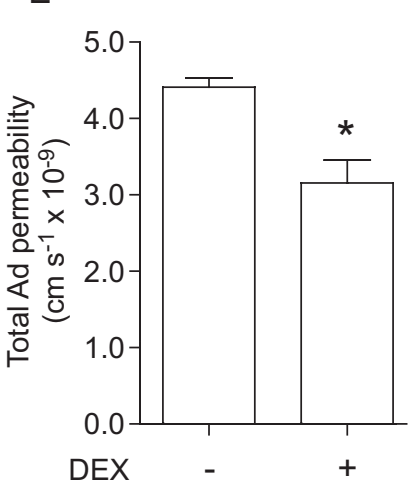

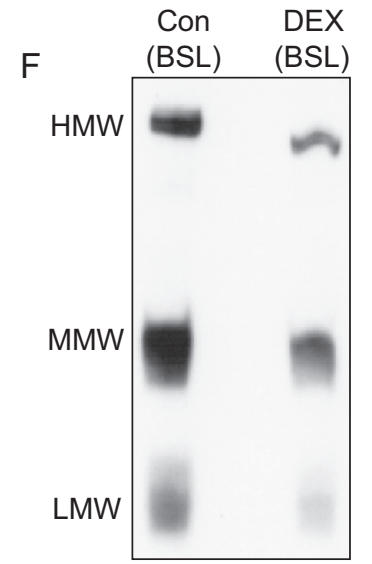

\section{Figure 1}

Effects of DEX on permeability. HUVECs (Human Umbilical Vein Endothelial Cell) were seeded onto permeable polyethylene terephthalate (PET) filters and treated with or without $1 \mu \mathrm{M}$ of DEX every other day in both top and bottom of compartments. Tightness of the monolayer was measured on the 5th day of DEX treatment. (A) Transendothelial Electrical Resistance (TEER). (B) [3H]PEG-4000 permeability across HUVEC monolayer. (C) Measurements of hydraulic conductivity $(L P)$ in individually perfused mesenteric venules from normal $(n=6)$ and Dex-treated $(n=4)$ rats. DEX treatment significantly attenuated the Lp responses to PAF that was known to cause transient increases in Lp. (D, E and F) $10 \mu \mathrm{g}$ of full-length Ad was added onto the apical side. After $24 \mathrm{~h}$, the medium on basolateral was collected. (D) Total Ad amount was quantified using ELISA. (E) The collected basolateral medium was concentrated and separated by PAGE. 3 forms of Ad are labeled as LMW ( $90 \mathrm{kDa})$, MMW ( 180 kDa) and HMW (>250 kDa). (F) Representative Western blot for full-length Ad flux across control and Dex-treated monolayers. Data are expressed as mean values \pm S.E.M. $(n=4-8)$. *Significant difference $(P \leq 0.05)$ from control (Con) group. 
We then assessed flux of Ad from the apical to basolateral side of HUVEC monolayer and found a reduced total amount of Ad in basolateral media after DEX treatment (Fig. 1D, E and F). When monitoring absolute flux rates in control cells, Ad flux rate was $4.4 \pm 0.12 \mathrm{~cm} / \mathrm{s} \times 10^{-9}$, which significantly decreased after DEX treatment to $3.2 \pm 0.30 \mathrm{~cm} / \mathrm{s} \times 10^{-9}$ (Fig. 1D). Following a 24-h flux period, Ad levels detected in basolateral media were $64.8 \pm 5.7 \mathrm{ng} / \mathrm{mL}$. Using Western blotting to examine various oligomeric forms of Ad LMW ( $90 \mathrm{kDa})$, MMW $(\sim 180 \mathrm{kDa})$ and HMW (>250 kDa), we found that flux of all forms was reduced by DEX (Fig. 1E and F). Additionally, the functional activity of Ad appearing in basolateral media was confirmed by using this media to treat L6 skeletal muscle cells and H9C2 cells derived from rat heart ventricle. In both cell types, the media increased AMPK phosphorylation (Supplementary Fig. 1A and B, see section on supplementary data given at the end of this article).

\section{Dexamethasone treatment alters transcript and protein abundance of select TJ proteins in HUVEC monolayers}

A tissue expression profile of transcripts encoding $26 \mathrm{TJ}$ proteins in HUVECs revealed the presence of 15 (Fig. 2A). The most abundant transcript was found to be Cldn-11, while Cldn-7, Cldn-12 and ZO-1 exhibited relatively high abundance and OCLN, TRIC, CLDN-10 and CLDN-15 exhibited moderate levels of abundance (Fig. 2A). Transcripts not detected in HUVECs included CLDN-3, $-4,-5,-8,-9,-16,-17,-18,-19,-23$ and -25 (Fig. $2 \mathrm{~A}$ and Supplementary Fig. 1C). Human kidney cDNA was used as a positive control for transcripts that were not detected in HUVECs (Supplementary Fig. 1C). To explore the response of TJ proteins to DEX treatment, we first compared mRNA abundance of expressed target genes in HUVECs. DEX increased $C L D N-6$ mRNA abundance while $C L D N-2,-20$, $-22,-24$ and ZO-1 mRNA showed significant decreases (Fig. 2B). DEX treatment had no significant effect on mRNA encoding OCLN, TRIC, CLDN-1, -7, -10, -11, -12
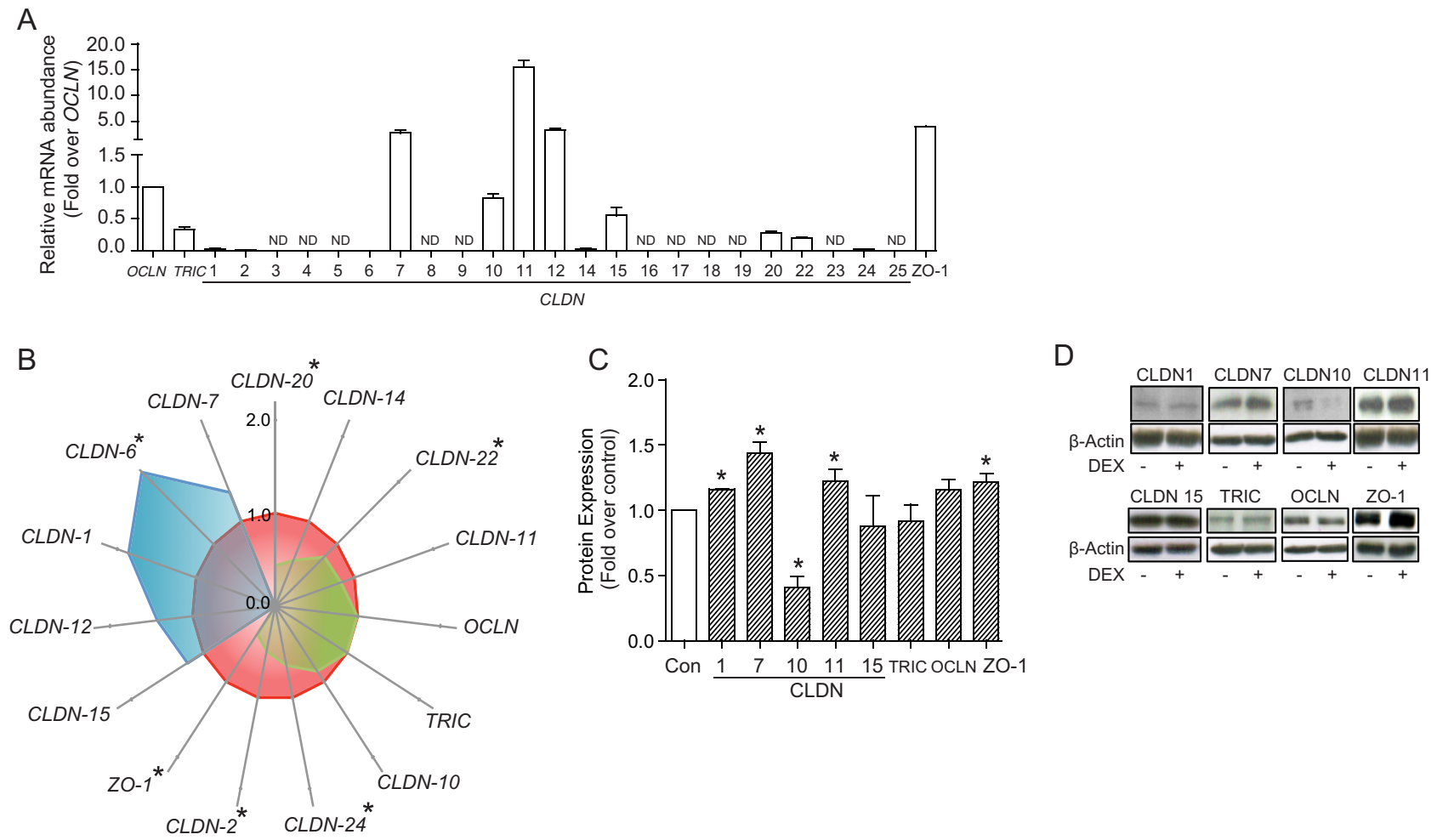

Figure 2

Effect of DEX on tight junction components. (A) mRNA abundance by qRT-PCR analysis. HUVECs grown to confluence on permeable PET inserts. Total RNA was isolated from control cells on the 5th day. Transcript abundance was normalized to GAPDH and each gene examined was expressed relative to OCLN transcript abundance. (B) TJ transcript levels in DEX-treated cells were normalized to GAPDH, and expressed relative to the control group (blue increasing compared to control; green - decreasing compared to control). Data are expressed as mean values \pm S.E.M. ( $n=3-5)$. (C) Protein abundance in HUVECs grown on cell culture inserts. Protein abundance were normalized to $\beta$-ACTIN, and expressed relative to the control group. (D) Representative Western blots of CLDN-1, $-7,-10,-11,-15$, TRI, OCC, ZO-1. Data are expressed as mean values \pm S.E.M. $(n=3-8)$. *Indicates significant difference $(P \leq 0.05)$ from control (Con) group. 
A

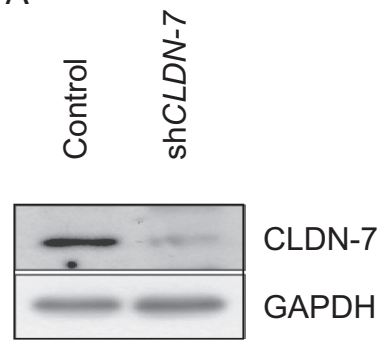

B

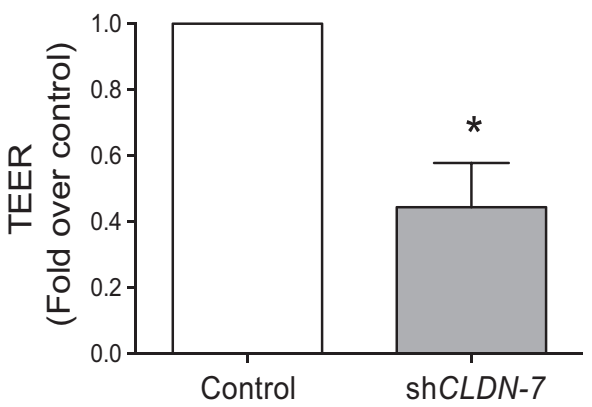

C

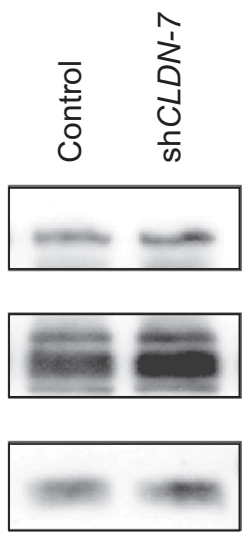

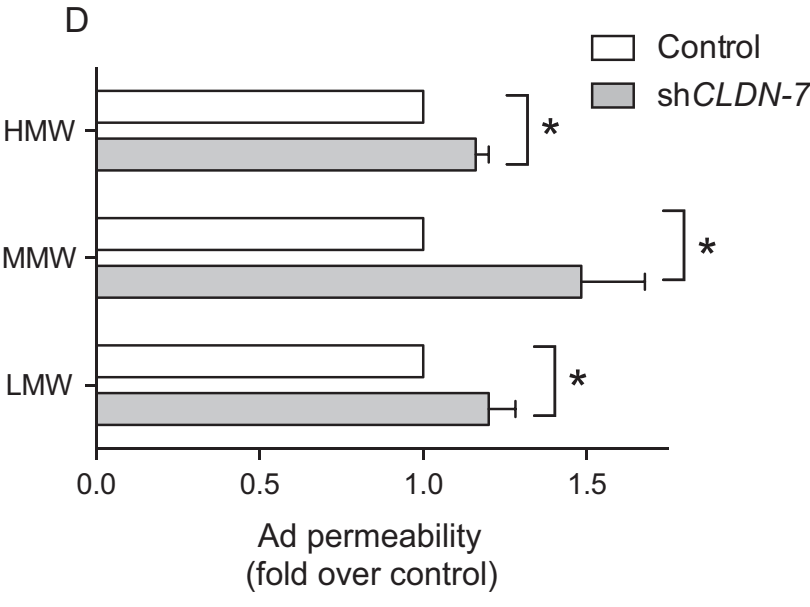

\section{Figure 3}

Knockdown of claudin-7 alters transendothelial electrical resistance and adiponectin flux. We used shRNA to reduce levels of claudin-7 in HUVEC and average efficiency of knockdown was $71 \%$ with a representative Western blot shown in A. In cells transfected with scrambled (Control) or claudin-7 shRNA, we then tested TEER (B) and flux of adiponectin with representative Western blot shown in $\mathrm{C}$ and quantitation in (D). In (B) and (D), values are mean \pm s. E.M. $(n=3)$ and *indicates significant difference $(P \leq 0.05)$ from control group. and -15 (Fig. 2B). Following DEX treatment, the protein abundance of CLDN-1, -7, -11 and ZO-1 was examined and found to be significantly upregulated following DEX treatment when compared to the control group (Fig. 2C and D). On the other hand, CLDN-10 protein levels were significantly decreased when compared with the expression in control conditions (Fig. 2C and D). In order to validate the functional significance of Dex-induced changes in the expression of tight junction proteins, we used shRNA to target claudin-7 and this effectively reduced its expression by $71 \%$ on average (Fig. 3A). Furthermore, HUVEC with reduced levels of claudin-7 showed reduced TEER and a small but significant increase in flux of adiponectin from apical to basolateral side (Fig. 3B, C and D).

\section{Examination of changes in transcellular endothelial flux}

The possible contribution of transcellular receptormediated Ad movement across HUVEC monolayers was then investigated by analysis of expression levels of three identified Ad receptors. Intracellular Ad content in these cells was detected, although at low level, and expression levels did not change significantly with DEX treatment
(Fig. 4A). However, DEX significantly increased T-cadherin protein abundance (Fig. 4B), but had no effect on protein abundance of AdipoR1 and AdipoR2 (Fig. 4C).

\section{Skeletal muscle Ad content in a rat model of exogenous glucocorticoid-induced diabetes}

We then examined whether the increased endothelial cell barrier tightness observed after DEX treatment would be paralleled in a diabetic rodent model of chronic glucocorticoid exposure. As expected based on previously published work (D'Souza et al. 2012, Shikatani et al. 2012, Shpilberg et al. 2012), two weeks of exogenous corticosterone (CORT) treatment resulted in severe fasting hyperinsulinemia and impaired glucose tolerance (Supplementary Fig. 2A). In addition, CORT treatment caused mild/moderate elevations in fasted blood glucose concentrations $(5.12 \pm 0.2-8.3 \pm 1.88 \mathrm{mM}$, Supplementary Fig. 2B) despite the significantly increased fasted insulin concentrations $(0.76 \pm 0.25-4.68 \pm 0.72 \mathrm{ng} / \mathrm{mL}$, Supplementary Fig. 2C). CORT treatment also caused a change in skeletal muscle fiber type composition, a switch from predominantly slow- to fast-twitch skeletal 
A
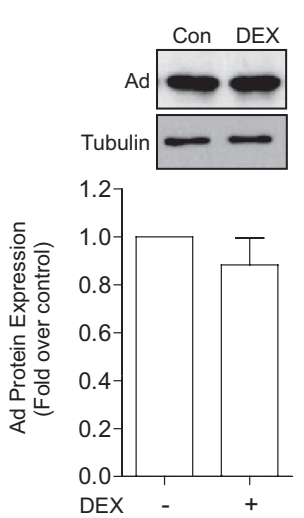

B
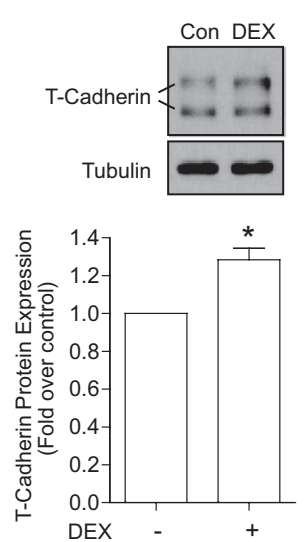

C
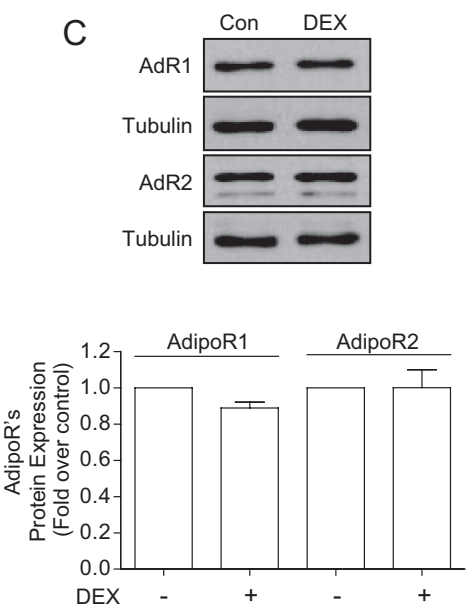

Figure 4

Expression of $\mathrm{Ad}$ and its receptors in HUVEC. (A) Ad expression in HUVECs treated with DEX after 5 days. (B) T-CADHERIN expression in HUVECs with DEX treatment. (C) ADIPO-R1/-R2 expression in HUVECs. Data are expressed as mean values \pm s.E.M. $(n=3-6)$. *Indicates significant difference $(P \leq 0.05)$ from control (Con) group.
A

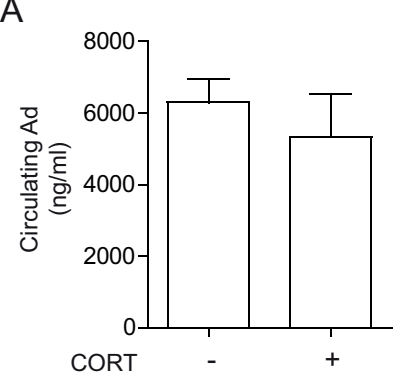

C

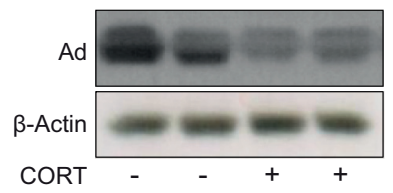

$\mathrm{F}$

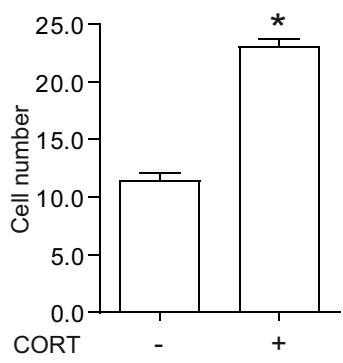

B

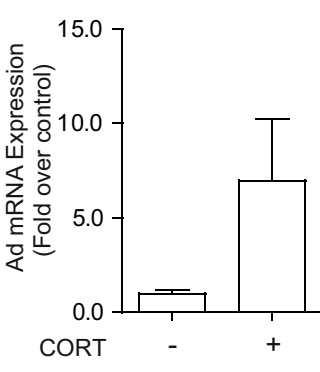

D

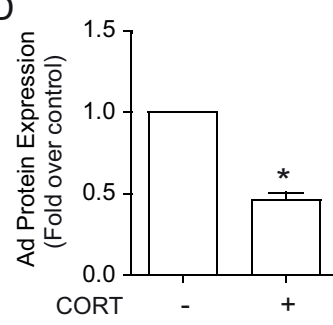

G

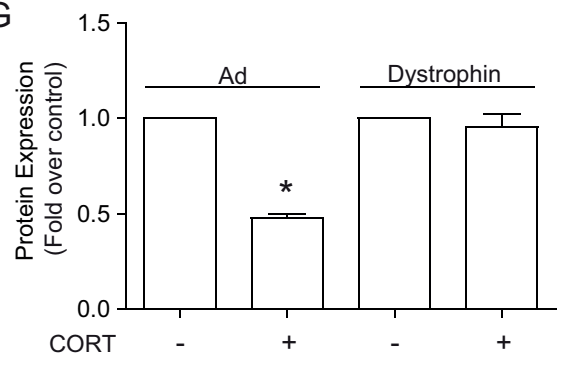

E
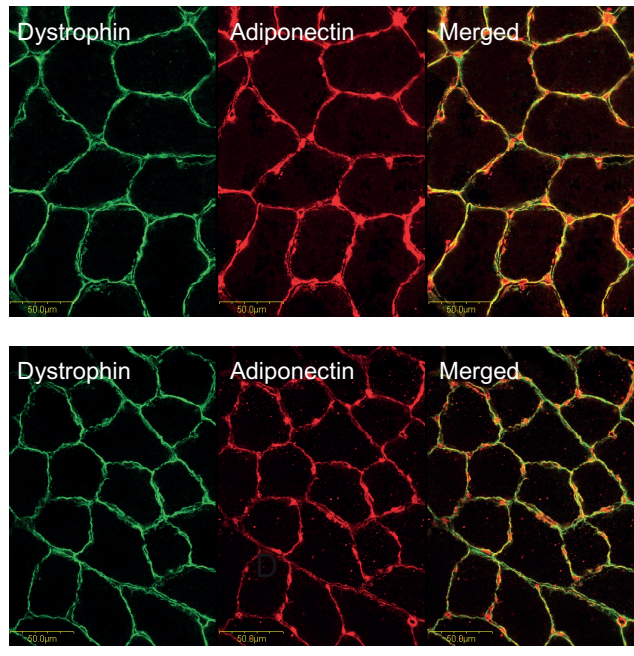

$\mathrm{H}$

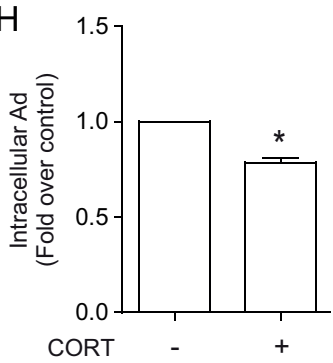

Figure 5

Ad level in CORT-treated animals. (A) Using ELISA, circulating Ad was calculated in 1-week treated rat serum. (B) Ad mRNA expression after 14 days of CORT. (C and D) Representative Western blotting and quantitation of reduced $\mathrm{Ad}(\sim 30 \mathrm{kDa})$ in soleus skeletal muscle. (E) Immunohistochemical detection of dystropin (green), Ad (red) in skeletal muscle isolated from rats after 2 weeks of CORT treatment, together with quantitation in F. (G) Quantification of changes in intracellular Ad levels and $(\mathrm{H})$ cell number. Quantification of Ad shown as the intensity expressed per cell in arbitrary units and is expressed as mean values \pm S.E.M. $(n=3-5)$. *Indicates significant difference $(P \leq 0.05)$ from control (Con) group. 
muscle fibers, within the tibialis anterior muscle (Supplementary Fig. 2D).

To explore whether CORT treatment affects circulating Ad levels, we measured plasma Ad levels in these animals before CORT pellet implantation and at 7 days post pellet implantation, at 08:00 h. Circulating Ad levels were unaffected by CORT treatment (Fig. 5A). Interestingly, there was an apparent elevation in skeletal muscle Ad mRNA levels (Fig. 5B), yet Ad protein content was significantly reduced (Fig. 5C and D). Upon immunohistochemical analyses, we also observed that the total amount of Ad was decreased in skeletal muscle from the CORT-treated rats vs control rats (Fig. 5E, F, $\mathrm{G}$ and $\mathrm{H})$. Dystropin was used to assess the structural integrity of the skeletal muscle and was unaffected by CORT treatment. Representative images are shown (Fig. 5E) with quantification of the total and intracellular Ad signal (Fig. 5G and H). Since CORT treatment is known to preferentially target fast-twitch skeletal muscle
(Beaudry et al. 2015), representative images accordingly depict smaller IIb/x fiber area (Fig. 4D) within the CORT-treated rats. CORT treatment was also found to cause a significant reduction in individual myocyte size (Fig. 5F).

\section{Adipo $R$ abundance in a rat model of exogenous glucocorticoid-induced diabetes}

Both Ad receptor isoforms (AdipoR1 and AdipoR2) genes were expressed in rat soleus skeletal muscle and although an apparent increase in AdipoR1 mRNA abundance was seen in the diabetic rat model, neither was significantly altered (Fig. 6A and B). However, a significantly increased level of ADIPO-R1 protein (approximately 3.4 fold compared to the control) was seen (Fig. 6F). There were no changes in ADIPO-R2 nor in T-Cadherin protein levels (Fig. 6E and G).
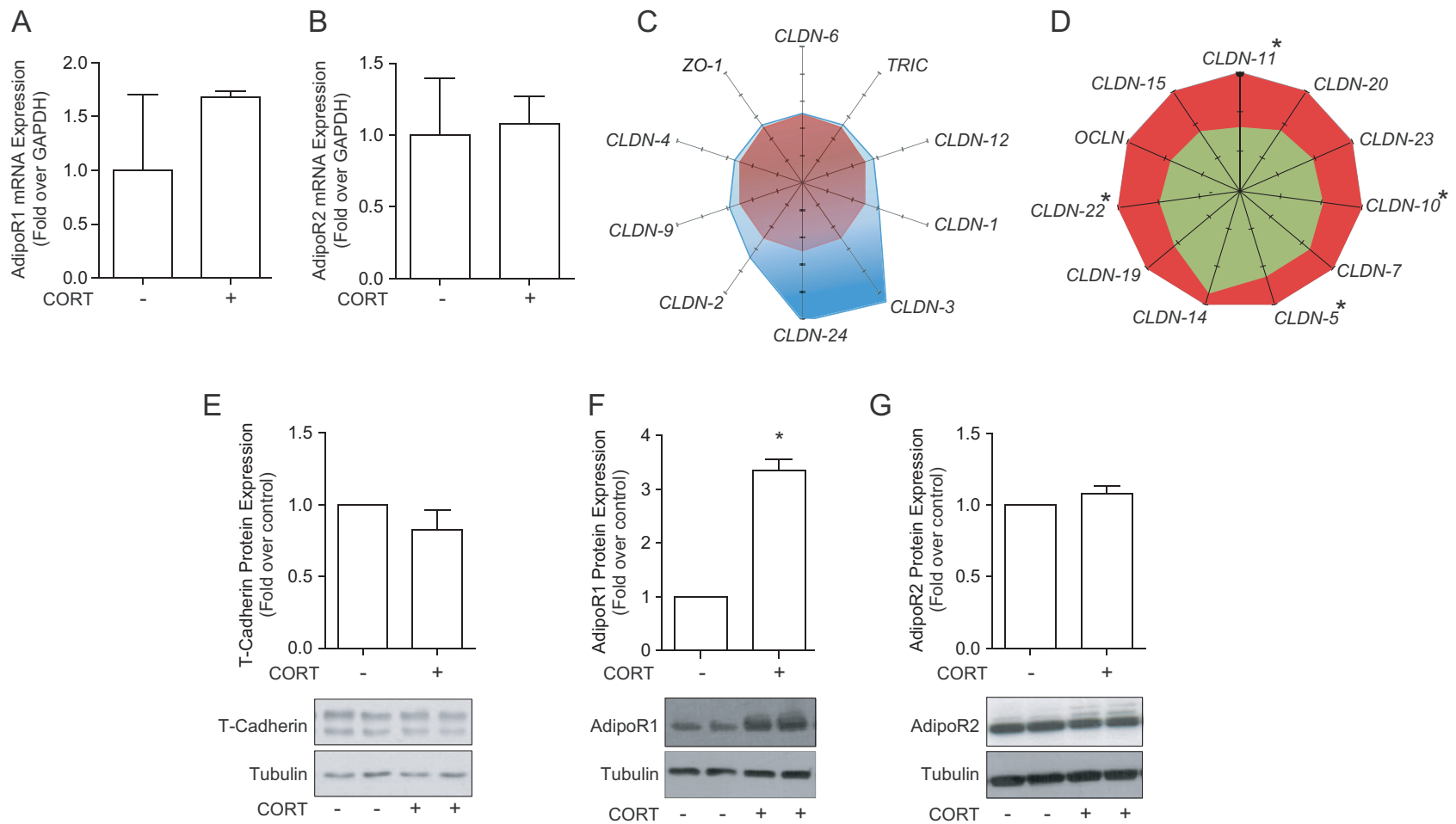

\section{Figure 6}

Ad receptor expression in skeletal muscle. Rats were treated with CORT for 2 weeks. (A and B) mRNA expression of Ad and its receptors after 14 days of CORT. Data are expressed as mean values \pm s.E.m. $(n=4-5)$. (C and D) mRNA profile of tight junction in soleus skeletal muscle isolated from 2 weeks CORT-treated rats. mRNA abundance by qRT-PCR analysis. Transcript abundance was normalized to GAPDH mRNA abundance, and mRNA abundance for each gene examined was expressed relative to control group transcript abundance. Control group gene transcript was normalized to 1. (C) mRNA profile of TJ that is increased after 2-week CORT treatment compared to control (blue - CORT-treated, red - Control. (D) TJ genes that are decreased after 2 weeks of CORT treatment. (E, F and G) Protein expression in soleus. (E) T-CADHERIN. (F) Ad receptor 1. (G) Ad receptor 2. Data are expressed as mean values \pm S.E.M. $(n=3)$. *Indicates significant difference $(P \leq 0.05)$ from control group. 


\section{CORT treatment altered tight junction genes in rat soleus skeletal muscle after 2 weeks}

We then measured changes in transcript abundance of tight junctions components, Cldn-1, -2, -3, -4, -5, -6, -7, $-9,-10,-11,-12,-24,-14,-15,-19,-20,-22,-23$ and Ocln, Tricand ZO-1 were found to have no significant changes within diabetic rat skeletal muscle (Fig. 6C), whereas Cldn-5, -10, -11, -22 significantly decreased (Fig. 6D).

\section{Discussion}

Glucocorticoids are potential mediators of endothelium permeability. Our study was designed investigate its influence on endothelium permeability and consequently the changes in Ad movement across the endothelium barrier and the underlying mechanism. More recently, a similar proposed mechanism for regulation of Ad action was suggested both by us and others (Rutkowski et al. 2014, Yoon et al. 2014). To the best of our knowledge, the regulation of this process by glucocorticoids had not been studied before. Our vitro model using DEXtreated HUVEC and CORT-treated rats to integrate the established observations that glucocorticoids can restrict paracellular transport across various endothelia (Keaney \& Campbell 2015, Rao et al. 2015, Rochfort \& Cummins 2015) with the fact that glucocorticoids, commonly prescribed medications, have numerous side effects, including insulin resistance and diabetes (Beaudry et al. 2015). Furthermore, we examined whether the emerging phenomenon that transendothelial movement of $\mathrm{Ad}$ may regulate the anti-diabetic effects of this hormone and whether this was regulated by glucocorticoids (Rutkowski et al. 2014, Yoon et al. 2014). Specifically, our approach involved the use of endothelial cell monolayers and individually perfused intact microvessels to examine whether glucocorticoid-altered Ad flux was through reduced microvessel permeability. We also used a rat model of diabetes induced by exogenous glucocorticoid treatment to determine changes in Ad content in muscle as well as peripheral insulin sensitivity.

As indicated in the introduction, strong rationale for this work comes from previousstudies with other circulating hormones, most notably insulin. Concentrations of insulin at the cell surface have been shown to be very different from those observed in plasma in microdialysis experiments (Sjostrand et al. 1999, Herkner et al. 2003), direct interstitial sampling (Bodenlenz et al. 2005) and lymph measurements (Yang et al. 1994, Chiu et al. 2008).
It was noted that insulin-mediated glucose uptake lagged behind the increase in plasma insulin (Freidenberg et al. 1994), whereas in cultured skeletal muscle cells, insulin-mediated glucose uptake occurs within $10 \mathrm{~min}$ (Somwar et al. 2001). The time delay seen in vivo (Freidenberg et al. 1994) reflects a delay in insulin access to the myocyte which is mediated in part via altered paracellular or transcellular endothelial transport. Thus, modification of access to skeletal muscle can have major effects on insulin action and metabolism, suggesting that reaching the interstitial space is the limiting factor for insulin-mediated glucose uptake (Kolka \& Bergman 2012). Indeed, delivery of insulin to the interstitial space has been shown to be altered by diet (Kubota et al. 2011).

We confirmed the ability of the synthetic glucocorticoid DEX to alter endothelial transport properties, in this case of HUVEC monolayers, as indicated by changes in TEER and PEG-4000. Similar effects were observed in DEX-treated rats, where we saw a significant reduction of permeability in rat mesenteric venules. We then showed that DEX reduced Ad flux across cultured endothelial monolayers by ELISA detection of total Ad content. Western blotting of Ad isoforms indicated that all three oligomeric forms of Ad (trimer, hexamer and oligomer) were reduced in basolateral media from DEXtreated cells, and although the magnitude of change was more evident in the case of LMW adiponectin, all isoforms were significantly altered and we do not believe these data infer a preferential restriction of LMW flux. This demonstration of restricted flux is important to establish from several perspectives. First, many studies have suggested that oligomeric high-molecular-weight complexes of Ad are most tightly correlated with insulin resistance (Pajvani et al. 2004, Liu et al. 2007). Second, the concept that endothelial transport regulated Ad action was also proposed by a recent study, which estimated the size of different Ad forms by calculating a Stokes radius (Rutkowski et al. 2014). The Stokes radii were $3.96 \mathrm{~nm}$ for trimeric Ad, $6.01 \mathrm{~nm}$ for hexameric Ad and $10.1 \mathrm{~nm}$ for various HMW oligomeric forms (Rutkowski et al. 2014), and these sizes are likely to be in the range that can be physically obstructed or facilitated by changes in endothelial cell tight junction size. Indeed, it was concluded that Ad bioavailability and action in target cells were attenuated under stressed conditions due to reduced transendothelial transport (Rutkowski et al. 2014). We concur that the regulation of Ad flux across endothelium is particularly relevant since the target tissues where Ad mediates its physiological effects have a http://joe.endocrinology-journals.org DOI: 10.1530/JOE-16-0363
๑ 2017 Society for Endocrinology Printed in Great Britain
Published by Bioscientifica Ltd 
wide range of endothelial permeability. Liver, for example, has highly fenestrated endothelium that may permit the passage of HMW Ad, which has potent effects on hepatic metabolism. In contrast, the central effects of HMW Ad may be limited by its transport across the comparatively tighter blood-brain barrier (Yoon et al. 2014).

The well-established effect of glucocorticoids to restrict endothelial transport has been proposed to be mediated via regulation of $\mathrm{TJ}$ and adherents junction (AJ) proteins (Felinski \& Antonetti 2005, Blecharz et al. 2008). Strands of transmembrane and cytosolic proteins form $\mathrm{TJ}$ and $\mathrm{AJ}$ complexes that regulate permeability between endothelial cells (Gunzel \& Fromm 2012). Functional characteristics of the vertebrate TJ complex are dependent on the variable assemblage of TJ proteins such as occludin (OCLN), tricellulin (TRIC) and, in particular, claudins (CLDNs), which directly establish the TJ barrier and form the backbone of TJ strands, while cytosolic ZO-1 and other cortical TJ proteins provide structural support to the TJ complex (Gunzel \& Fromm 2012). The CLDN superfamily consists of at least 27 isoforms in mammals and the incorporation of specific CLDN isoforms in TJs can modulate TJ barrier function by making the paracellular pathway tighter or leakier (Gunzel \& Yu 2013). The main observations in our study were increased CLDN-7 and decreased CLDN-10 protein abundance in HUVEC in response to DEX, and these changes may underlie the functional properties of paracellular transport limiting Ad flux. Little is known about CLDN-7, although CLDN-7 knockout is lethal in murine models, and it seems that CLDN-7 most likely facilitates anion movement across vertebrate epithelia. CLDN-7 was previously found to form a complex with the epithelial cell adhesion molecule (EpCAM), which enhanced cell-cell interaction (Krug et al. 2012, Verma \& Molitoris 2015). We suggested that the functional role of CLDN-7 in our model is tightening of the endothelium in association with an increase in abundance, and that this may help to explain, in part, the restricted movement of Ad in DEX-treated HUVEC as well CORT-treated rats. Further supporting this idea, a previous study has found that CLDN-7 (-/-) can cause colonic inflammation and enhance the paracellular flux of small organic solutes (Tanaka et al. 2015), as well as observations that CLDN-7 $(-/-)$ results in the presence of intercellular gaps below TJs and cell matrix loosening (Ding et al. 2012). Thus, we used shRNA to target claudin-7 in HUVEC and observed that this caused a decrease in TEER and increase in adiponectin flux across monolayers, further indicating an important mechanistic role for Dex-mediated changes in claudin-7 expression. Interestingly, another group found that NLRP3 inflammasome promoted endothelial disruption via production of HMGB1 to disrupt the junctions and increased paracellular permeability (Chen et al. 2015). Finally, Tatum and cowokers (Tatum et al. 2010) reported that urine $\mathrm{Na}(+), \mathrm{Cl}(-)$ and $\mathrm{K}(+)$ were significantly increased in CLDN-7(-/-) mice compared with those of CLDN-7(+/+) mice. Taken together, the studies outlined above and our data indicate an important functional consequence for CLDN-7 reduction and compromised epithelial permeability as the result of tight junction disruption, and this supports the view that increased CDLN-7 abundance, as seen in these experiments, may contribute to endothelial tightening and reduced Ad flux.

In contrast, CLDN-10 isoforms in vertebrate epithelia have been described to impart both chargeand size-selective properties to the paracellular pathway. Previous studies investigated the role of CLDN-10deficient mice using Cre-Lox and found that serum phosphate concentration was 28\% higher and serum $\mathrm{Mg}^{2+}$ concentration was almost twofold higher in $\mathrm{cKO}$ mice compared with controls. However, the same study also found that CLDN-10 transports molecules in a charged selective manner (Breiderhoff et al. 2012). To the best of our knowledge, Ad is uncharged. Therefore, the transport of Ad is less likely to be affected by CLDN-10. Nevertheless, it would be very interesting to explore whether the consistent decrease in CLDN-10 observed in this study has a functional role in the modulation of $\mathrm{Ad}$ transport across the endothelium barrier.

In the glucocorticoid-induced diabetic rodent model used here, a decrease in CLDN-10 mRNA expression in skeletal muscle was also observed. Although changes in expression profiles of other tight junction proteins do not entirely match the changes in HUVEC treated directly with DEX, this is not entirely surprising since there are multiple factors impinging upon tight junction protein expression in skeletal muscle tissue in vivo.

We believe that reduced paracellular transport is the main mechanism of reduced Ad flux observed, yet we also tested possible indicators of altered transendothelial flux (Yoon et al. 2014). In DEX-treated endothelial cells, there was no major change in ADIPO-R1 or ADIPO-R2 mRNA and protein expression, although in skeletal muscle homogenates, ADIPO-R1 protein expression levels increased significantly in CORT-treated animals. This may reflect a compensatory mechanism to reduced Ad availability in order to increase sensitivity to available

Published by Bioscientifica Ltd 
Ad. We also observed that DEX increased expression of T-cadherin in HUVEC. T-cadherin has been identified as a non-functional receptor for Ad (Hug et al. 2004). This is in agreement with a previous study showing that DEX enhanced T-cadherin expression in human osteosarcoma cells (Bromhead et al. 2006). One possible interpretation of our finding is that binding to endothelial T-cadherin may trap Ad in the vasculature, as has recently been proposed (Matsuda et al. 2015).

We also investigated potential alterations in endothelial transport of $\mathrm{Ad}$ in a rodent model of glucocorticoid-induced diabetes (Shpilberg et al. 2012). In these rats, we found normal circulating Ad levels but significantly reduced total Ad protein content within skeletal muscle without an accompanying decrease in muscle Ad gene expression. This suggests that less flux of Ad from circulation could be a contributory mechanism. Indeed, upon immunohistochemical analysis, we found reduced Ad content in the interstitial space. Although not a direct comparison to the in vitro studies we used here, it suggests that skeletal muscle Ad availability, and thus action, may be limited in this animal model possibly contributing to its diabetic phenotype (Shpilberg et al. 2012, Beaudry et al. 2013, 2014, 2015, Yoon et al. 2014).

In conclusion, our study indicates that glucocorticoidmediated tightening can reduce flux of Ad across endothelial monolayers, and that this may be due to alterations in the expression profile of tight junction proteins. Furthermore, in a rat model of diabetes induced by exogenous glucocorticoids, we observed reduced interstitial and intracellular levels of Ad in skeletal muscle. Thus, we propose that reduced Ad action in target tissues, as a consequence of reduced endothelial flux from circulation to interstitial space, may contribute to the diabetic phenotype occurring after glucocorticoid treatment. Since glucocorticoids are one of the most commonly prescribed medications, our discovery of reduced Ad transport in response to glucocorticoids is a particularly important and novel finding with potentially far-reaching consequences.

Supplementary data

This is linked to the online version of the paper at http://dx.doi.org/10.1530/ JOE-16-0363.

\section{Declaration of interest}

The authors declare that there is no conflict of interest that could be perceived as prejudicing the impartiality of the research reported.

\section{Funding}

This work was initially funded by an operating grant to $\mathrm{G} S$ from Canadian Institutes of Health Research and then by Natural Science and Engineering Research Council of Canada Discovery Grants to G S, S P K and M C R. P H was funded by the National Institutes of Health (US) HL56237 and DK097391. G S also acknowledges Career Investigator support from Heart \& Stroke Foundation of Ontario.

\section{Acknowledgements}

We also greatly appreciate the contribution of $\mathrm{Dr}$ Tara Haas via advice on quantifications of skeletal muscle tissue immunostaining.

\section{References}

Agarwal A, Sarwar S, Sepah YJ \& Nguyen QD 2015 What have we learnt about the management of diabetic macular edema in the antivascular endothelial growth factor and corticosteroid era? Current Opinion in Ophthalmology 26 177-183. (doi:10.1097/ ICU.0000000000000152)

Arita Y, Kihara S, Ouchi N, Maeda K, Kuriyama H, Okamoto Y, Kumada M, Hotta K, Nishida M, Takahashi M, et al. 2002 Adipocyte-derived plasma protein adiponectin acts as a platelet-derived growth factorBB-binding protein and regulates growth factor-induced common postreceptor signal in vascular smooth muscle cell. Circulation 105 2893-2898. (doi:10.1161/01.CIR.0000018622.84402.FF)

Barrett EJ, Wang H, Upchurch CT \& Liu Z 2011 Insulin regulates its own delivery to skeletal muscle by feed-forward actions on the vasculature. American Journal of Physiology: Endocrinology and Metabolism 301 E252-E263. (doi:10.1152/ajpendo.00186.2011)

Beaudry JL, D'Souza AM, Teich T, Tsushima R \& Riddell MC 2013 Exogenous glucocorticoids and a high-fat diet cause severe hyperglycemia and hyperinsulinemia and limit islet glucose responsiveness in young male Sprague-Dawley rats. Endocrinology 154 3197-3208. (doi:10.1210/en.2012-2114)

Beaudry JL, Dunford EC, Leclair E, Mandel ER, Peckett AJ, Haas TL \& Riddell MC 2015 Voluntary exercise improves metabolic profile in high-fat fed glucocorticoid-treated rats. Journal of Applied Physiology (1985) 118 1331-1343. (doi:10.1152/japplphysiol.00467.2014)

Beaudry JL, Dunford EC, Teich T, Zaharieva D, Hunt H, Belanoff JK \& Riddell MC 2014 Effects of selective and non-selective glucocorticoid receptor II antagonists on rapid-onset diabetes in young rats. PLoS ONE 9 e91248. (doi:10.1371/journal.pone.0091248)

Blecharz KG, Drenckhahn D \& Forster CY 2008 Glucocorticoids increase VE-cadherin expression and cause cytoskeletal rearrangements in murine brain endothelial cEND cells. Journal of Cerebral Blood Flow and Metabolism 28 1139-1149. (doi:10.1038/jcbfm.2008.2)

Bodenlenz M, Schaupp LA, Druml T, Sommer R, Wutte A, Schaller HC, Sinner F, Wach P \& Pieber TR 2005 Measurement of interstitial insulin in human adipose and muscle tissue under moderate hyperinsulinemia by means of direct interstitial access. American Journal of Physiology: Endocrinology and Metabolism 289 E296-E300. (doi:10.1152/ajpendo.00431.2004)

Breiderhoff T, Himmerkus N, Stuiver M, Mutig K, Will C, Meij IC, Bachmann S, Bleich M, Willnow TE \& Muller D 2012 Deletion of claudin-10 (Cldn10) in the thick ascending limb impairs paracellular sodium permeability and leads to hypermagnesemia and nephrocalcinosis. PNAS 109 14241-14246. (doi:10.1073/ pnas.1203834109)

Bromhead C, Miller JH \& McDonald FJ 2006 Regulation of T-cadherin by hormones, glucocorticoid and EGF. Gene 374 58-67. (doi:10.1016/j. gene.2006.01.013) http://joe.endocrinology-journals.org DOI: 10.1530/JOE-16-0363
๑) 2017 Society for Endocrinology Printed in Great Britain 
Chen Y, Pitzer AL, Li X, Li PL, Wang L \& Zhang Y 2015 Instigation of endothelial Nlrp3 inflammasome by adipokine visfatin promotes inter-endothelial junction disruption: role of HMGB1. Journal of Cellular and Molecular Medicine 19 2715-2727. (doi:10.1111/ jcmm.12657)

Chiu JD, Richey JM, Harrison LN, Zuniga E, Kolka CM, Kirkman E, Ellmerer M \& Bergman RN 2008 Direct administration of insulin into skeletal muscle reveals that the transport of insulin across the capillary endothelium limits the time course of insulin to activate glucose disposal. Diabetes 57 828-835. (doi:10.2337/db07-1444)

Clark AR \& Belvisi MG 2012 Maps and legends: the quest for dissociated ligands of the glucocorticoid receptor. Pharmacology and Therapeutics 134 54-67. (doi:10.1016/j.pharmthera.2011.12.004)

D'Souza A M, Beaudry JL, Szigiato AA, Trumble SJ, Snook LA, Bonen A, Giacca A \& Riddell MC 2012 Consumption of a high-fat diet rapidly exacerbates the development of fatty liver disease that occurs with chronically elevated glucocorticoids. American Journal of Physiology: Gastrointestinal and Liver Physiology 302 G850-G863. (doi:10.1152/ ajpgi.00378.2011)

Dadson K, Liu Y \& Sweeney G 2011 Adiponectin action: a combination of endocrine and autocrine/paracrine effects. Frontiers in Endocrinology 262.

Ding L, Lu Z, Foreman O, Tatum R, Lu Q, Renegar R, Cao J \& Chen YH 2012 Inflammation and disruption of the mucosal architecture in claudin-7-deficient mice. Gastroenterology 142 305-315. (doi:10.1053/j.gastro.2011.10.025)

Felinski EA \& Antonetti DA 2005 Glucocorticoid regulation of endothelial cell tight junction gene expression: novel treatments for diabetic retinopathy. Current Eye Research 30 949-957. (doi:10.1080/02713680500263598)

Freidenberg GR, Suter S, Henry RR, Nolan J, Reichart D \& Olefsky JM 1994 Delayed onset of insulin activation of the insulin receptor kinase in vivo in human skeletal muscle. Diabetes 43 118-126. (doi:10.2337/diab.43.1.118)

Gunzel D \& Fromm M 2012 Claudins and other tight junction proteins. Comprehensive Physiology 2 1819-1852.

Gunzel D \& Yu AS 2013 Claudins and the modulation of tight junction permeability. Physiological Reviews 93 525-569. (doi:10.1152/ physrev.00019.2012)

Herkner H, Klein N, Joukhadar C, Lackner E, Langenberger H, Frossard M, Bieglmayer C, Wagner O, Roden M \& Muller M 2003 Transcapillary insulin transfer in human skeletal muscle. European Journal of Clinical Investigation 33 141-146. (doi:10.1046/j.1365-2362.2003.01106.x)

Hug C, Wang J, Ahmad NS, Bogan JS, Tsao TS \& Lodish HF 2004 T-cadherin is a receptor for hexameric and high-molecular-weight forms of Acrp30/adiponectin. PNAS 101 10308-10313. (doi:10.1073/ pnas.0403382101)

Kadowaki T, Yamauchi T, Kubota N, Hara K, Ueki K \& Tobe K 2006 Adiponectin and adiponectin receptors in insulin resistance, diabetes, and the metabolic syndrome. Journal of Clinical Investigation 116 1784-1792. (doi:10.1172/JCI29126)

Keaney J \& Campbell M 2015 The dynamic blood-brain barrier. FEBS Journal 282 4067-4079. (doi:10.1111/febs.13412)

Kolka CM \& Bergman RN 2012 The barrier within: endothelial transport of hormones. Physiology 27 237-247. (doi:10.1152/ physiol.00012.2012)

Krause MP, Liu Y, Vu V, Chan L, Xu A, Riddell MC, Sweeney G \& Hawke TJ 2008 Adiponectin is expressed by skeletal muscle fibers and influences muscle phenotype and function. American Journal of Physiology: Cell Physiology 295 C203-C212. (doi:10.1152/ ajpcell.00030.2008)

Krug SM, Gunzel D, Conrad MP, Lee IF, Amasheh S, Fromm M \& Yu AS 2012 Charge-selective claudin channels. Annals of the New York Academy of Sciences 1257 20-28. (doi:10.1111/j.17496632.2012.06555.x)
Kubota N, Yano W, Kubota T, Yamauchi T, Itoh S, Kumagai H, Kozono H, Takamoto I, Okamoto S, Shiuchi T, et al. 2007 Adiponectin stimulates AMP-activated protein kinase in the hypothalamus and increases food intake. Cell Metabolism 6 55-68. (doi:10.1016/j.cmet.2007.06.003)

Kubota T, Kubota N, Kumagai H, Yamaguchi S, Kozono H, Takahashi T, Inoue M, Itoh S, Takamoto I, Sasako T, et al. 2011 Impaired insulin signaling in endothelial cells reduces insulin-induced glucose uptake by skeletal muscle. Cell Metabolism 13 294-307. (doi:10.1016/j. cmet.2011.01.018)

Kusminski CM, McTernan PG, Schraw T, Kos K, O'Hare JP, Ahima R, Kumar S \& Scherer PE 2007 Adiponectin complexes in human cerebrospinal fluid: distinct complex distribution from serum. Diabetologia 50 634-642. (doi:10.1007/s00125-006-0577-9)

Lin KT \& Wang LH 2016 New dimension of glucocorticoids in cancer treatment. Steroids 111 84-88. (doi:10.1016/j.steroids.2016.02.019)

Liu Y, Retnakaran R, Hanley A, Tungtrongchitr R, Shaw C \& Sweeney G 2007 Total and high molecular weight but not trimeric or hexameric forms of adiponectin correlate with markers of the metabolic syndrome and liver injury in Thai subjects. Journal of Clinical Endocrinology and Metabolism 92 4313-4318. (doi:10.1210/jc.20070890)

Matsuda K, Fujishima Y, Maeda N, Mori T, Hirata A, Sekimoto R, Tsushima Y, Masuda S, Yamaoka M, Inoue K, et al. 2015 Positive feedback regulation between adiponectin and T-cadherin impacts adiponectin levels in tissue and plasma of male mice. Endocrinology 156 934-946. (doi:10.1210/en.2014-1618)

Nanayakkara G, Kariharan T, Wang L, Zhong J \& Amin R 2012 The cardio-protective signaling and mechanisms of adiponectin. American Journal of Cardiovascular Disease 2 253-266.

Neumeier M, Weigert J, Buettner R, Wanninger J, Schaffler A, Muller AM, Killian S, Sauerbruch S, Schlachetzki F, Steinbrecher A, et al. 2007 Detection of adiponectin in cerebrospinal fluid in humans. American Journal of Physiology: Endocrinology and Metabolism 293 E965-E969. (doi:10.1152/ajpendo.00119.2007)

Ogilvie RW \& Feeback DL 1990 A metachromatic dye-ATPase method for the simultaneous identification of skeletal muscle fiber types I, IIA, IIB and IIC. Stain Technology 65 231-241. (doi:10.3109/10520299009105613)

Pajvani UB, Hawkins M, Combs TP, Rajala MW, Doebber T, Berger JP, Wagner JA, Wu M, Knopps A, Xiang AH, et al. 2004 Complex distribution, not absolute amount of adiponectin, correlates with thiazolidinedione-mediated improvement in insulin sensitivity. Journal of Biological Chemistry 279 12152-12162. (doi:10.1074/jbc. M311113200)

Peters KE, Beilby J, Cadby G, Warrington NM, Bruce DG, Davis WA, Davis TM, Wiltshire S, Knuiman M, McQuillan BM, et al. 2013 A comprehensive investigation of variants in genes encoding adiponectin (ADIPOQ) and its receptors (ADIPOR1/R2), and their association with serum adiponectin, type 2 diabetes, insulin resistance and the metabolic syndrome. BMC Medical Genetics 1415. (doi:10.1186/1471-2350-14-15)

Rao A, Pandya V \& Whaley-Connell A 2015 Obesity and insulin resistance in resistant hypertension: implications for the kidney. Advances in Chronic Kidney Disease 22 211-217. (doi:10.1053/j. ackd.2014.12.004)

Rochfort KD \& Cummins PM 2015 The blood-brain barrier endothelium: a target for pro-inflammatory cytokines. Biochemical Society Transactions 43 702-706. (doi:10.1042/BST20140319)

Rutkowski JM, Halberg N, Wang QA, Holland WL, Xia JY \& Scherer PE 2014 Differential transendothelial transport of adiponectin complexes. Cardiovascular Diabetology 13 47. (doi:10.1186/1475-284013-47)

Shikatani EA, Trifonova A, Mandel ER, Liu ST, Roudier E, Krylova A, Szigiato A, Beaudry J, Riddell MC \& Haas TL 2012 Inhibition of proliferation, migration and proteolysis contribute to corticosterone- http://joe.endocrinology-journals.org

DOI: 10.1530/JOE-16-0363
(C) 2017 Society for Endocrinology Printed in Great Britain
Published by Bioscientifica Ltd 
mediated inhibition of angiogenesis. PLOS ONE 7 e46625. (doi:10.1371/journal.pone.0046625)

Shpilberg Y, Beaudry JL, D'Souza A, Campbell JE, Peckett A \& Riddell MC 2012 A rodent model of rapid-onset diabetes induced by glucocorticoids and high-fat feeding. Disease Models and Mechanisms 5 671-680. (doi:10.1242/dmm.008912)

Sjostrand M, Holmang A \& Lonnroth P 1999 Measurement of interstitial insulin in human muscle. American Journal of Physiology $\mathbf{2 7 6}$ E151-E154.

Somwar R, Kim DY, Sweeney G, Huang C, Niu W, Lador C, Ramlal T \& Klip A 2001 GLUT4 translocation precedes the stimulation of glucose uptake by insulin in muscle cells: potential activation of GLUT4 via p38 mitogen-activated protein kinase. Biochemical Journal 359 639-649. (doi:10.1042/bj3590639)

Tanaka H, Takechi M, Kiyonari H, Shioi G, Tamura A \& Tsukita S 2015 Intestinal deletion of Claudin-7 enhances paracellular organic solute flux and initiates colonic inflammation in mice. Gut 64 1529-1538. (doi:10.1136/gutjnl-2014-308419)

Tatum R, Zhang Y, Salleng K, Lu Z, Lin JJ, Lu Q, Jeansonne BG, Ding L \& Chen YH 2010 Renal salt wasting and chronic dehydration in claudin-7-deficient mice. American Journal of Physiology: Renal Physiology 298 F24-F34. (doi:10.1152/ajprenal.00450.2009)

Verma SK \& Molitoris BA 2015 Renal endothelial injury and microvascular dysfunction in acute kidney injury. Seminars in Nephrology 35 96-107. (doi:10.1016/j.semnephrol.2015.01.010)

Wang Y, Xu A, Knight C, Xu LY \& Cooper GJ 2002 Hydroxylation and glycosylation of the four conserved lysine residues in the collagenous domain of adiponectin. Potential role in the modulation of its insulin-sensitizing activity. Journal of Biological Chemistry 277 19521-19529. (doi:10.1074/jbc.M200601200)

Witt KA \& Sandoval KE 2014 Steroids and the blood-brain barrier: therapeutic implications. Advances in Pharmacology 71 361-390.

Won SM, Lee JH, Park UJ, Gwag J, Gwag BJ \& Lee YB 2011 Iron mediates endothelial cell damage and blood-brain barrier opening in the hippocampus after transient forebrain ischemia in rats. Experimental and Molecular Medicine 43 121-128. (doi:10.3858/emm.2011.43.2.020)

Wood CM, Gilmour KM \& Pärt P 1998 Passive and active transport properties of a gill model, the cultured branchial epithelium of the freshwater rainbow trout (Oncorhynchus mykiss). Comparative Biochemistry and Physiology A 119 87-96.

Xu A, Yin S, Wong L, Chan KW \& Lam KS 2004 Adiponectin ameliorates dyslipidemia induced by the human immunodeficiency virus protease inhibitor ritonavir in mice. Endocrinology 145 487-494. (doi:10.1210/ en.2003-1140)

Yang YJ, Hope ID, Ader M \& Bergman RN 1994 Importance of transcapillary insulin transport to dynamics of insulin action after intravenous glucose. American Journal of Physiology 266 E17-E25.

Yoon N, Dang TQ, Chasiotis H, Kelly SP \& Sweeney G 2014 Altered transendothelial transport of hormones as a contributor to diabetes. Diabetes and Metabolism Journal 38 92-99. (doi:10.4093/dmj.2014.38.2.92)

Yuan D \& He P 2012 Vascular remodeling alters adhesion protein and cytoskeleton reactions to inflammatory stimuli resulting in enhanced permeability increases in rat venules. Journal of Applied Physiology (1985) 113 1110-1120. (doi:10.1152/japplphysiol.00102.2012)

Yuan D, Xu S \& He P 2014 Enhanced permeability responses to inflammation in streptozotocin-induced diabetic rat venules: Rhomediated alterations of actin cytoskeleton and VE-cadherin. American Journal of Physiology: Heart and Circulatory Physiology 307 H44-H53. (doi:10.1152/ajpheart.00929.2013)

Zhang X, Wang N, Schachat AP, Bao S \& Gillies MC 2014 Glucocorticoids: structure, signaling and molecular mechanisms in the treatment of diabetic retinopathy and diabetic macular edema. Current Molecular Medicine 14 376-384. (doi:10.2174/1566524014666140128114414)

Zhou X \& He P 2011 Temporal and spatial correlation of plateletactivating factor-induced increases in endothelial $[\mathrm{Ca}(2)(+)]$ i, nitric oxide, and gap formation in intact venules. American Journal of Physiology: Heart and Circulatory Physiology 301 H1788-H1797. (doi:10.1152/ajpheart.00599.2011)

Received in final form 26 April 2017 Accepted 10 May 2017 (c) 2017 Society for Endocrinology Printed in Great Britain 